\title{
Synthesis and Characterization of Titanium Dioxide Nanoparticles with a Dosimetry Study of their Ability to Enhance Radiation Therapy using a Low Energy X-ray Source
}

\author{
Asma M. Alturki ${ }^{1 *}$ and Rachid Ayad $^{2}$ \\ 1Department of Chemistry, Faculty of Science, University of Tabuk, Saudi Arabia;aallturky@ut.edu.sa \\ 2Department of Physics, Faculty of Science, University of Tabuk, Saudi Arabia; rayad@ut.edu.sa
}

\begin{abstract}
Objective: This study was undertaken to synthesize and characterize $\mathrm{TiO}_{2} \mathrm{NPs}$ and to study the interaction of $\mathrm{TiO}_{2} \mathrm{NPs}$ with radiation and then estimate the Dose-enhancement Factor (DEF) at different concentrations of NPs under low-energy excitation (14-35 kV). Methods: Titanium dioxide $\left(\mathrm{TiO}_{2}\right)$ Nanoparticles (NPs) were synthesized by the sol-gel method. The structure, particle size and crystal phase were evaluated by Scanning Electron Microscopy (SEM), Transmission Electron Microscopy (TEM) and X-ray Diffraction (XRD). Findings: The XRD pattern exhibited peaks that were assigned to analyse crystals with particle sizes from $2-10 \mathrm{~nm}$. The X-ray absorption of $\mathrm{TiO}_{2} \mathrm{NP}$ solutions and pure water were investigated. Solutions with $0,3.33,6.66$ and $20 \%$ of the $\mathrm{TiO}_{2} \mathrm{NPs}$ were used to study the X-ray absorption of the samples and the Dose Enhancement Factor (DEF) is evaluated. The experimental results showed that the X-ray absorption for solutions with $0,3.33,6.66$ and $20 \%$ of the $\mathrm{TiO}_{2}$ NPs increased with increasing concentration for generated beams from $14 \mathrm{kV}$ to $35 \mathrm{kV}$. Additionally, a Dose-enhancement Factor (DEF) was observed for low-energy beams between $14 \mathrm{kV}$ and $35 \mathrm{kV}$. TiO ${ }_{2} \mathrm{NPs}$ at very low energies (14-35 kV) able to display significantly enhanced X-ray absorption, resulting in a higher absorbed dose.

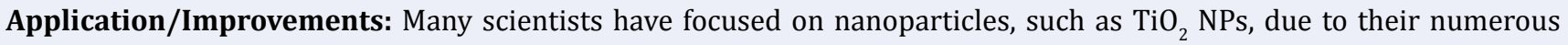
functions that enhance the nature of their antibacterial properties. Cancer is one of the reasons for human mortality. The main concept of cancer radiotherapy is the enhance radiation dose absorption at the targeted site by using high-Z materials.
\end{abstract}

Keywords: Dosimetry, Low Energy Source, Nanoparticles, Radiation Therapy, Titanium Dioxide

\section{Introduction}

Nanomaterials play a relevant role in different biomedical studies. NPs of metal oxide have attracted attention due to their unique properties. NPs can be synthesized by different methods, such as growth in solution, sol-gel, vapour deposition, pyrolysis and green biosynthesis methods ${ }^{1}$. Gold ( $\mathrm{Au}$ ) NPs (GNPs) as well as $\mathrm{ZnO}$ and $\mathrm{TiO}_{2}$ NPs have been widely used in cancer treatment and phototherapy because of their low cost, nontoxicity and stability ${ }^{2}$. Many scientists have focused on the characterization of nanoparticles, such as $\mathrm{TiO}_{2} \mathrm{NPs}$, due to their numerous functions that enhance the nature of their antibacterial properties ${ }^{3}$. Cancer is one of the reasons for human mortality. The main concept of cancer radiotherapy is the enhancement of the radiation dose by using high- $Z$ materials $s^{4}$. Therefore, we can deliver the maximum dose possible to cancer cells and still protect normal cells. Radiosensitization depends on the concentration and size of NPs as well as the photon energy ${ }^{5}$. A previous study testing the concept of high- $\mathrm{Z}$ materials in mice showed remarkable tumour abatement without toxicity for mice that were irradiated after the injection of GNPs compared with that for mice irradiated without GNPs ${ }^{6}$. The

${ }^{*}$ Author for correspondence 
DEF (Dose-enhancement Factor) was evaluated according to the following definition: The ratio of the average doses deposited in the tumour volume with and without nanoparticles after final irradiation ${ }^{7}$. Estimated the effects of GNPs on dose enhancement through radiation treatment at $140 \mathrm{kV}$ and $6 \mathrm{MV}$. The results showed that for Ir-192 at $140 \mathrm{keV}$, in the presence of GNPs, the dose enhancement for a tumour with $7 \mathrm{mg} \mathrm{Au} / \mathrm{g}$ was at least a factor of 2 and ranged from 1-7\% at 4-6 MV, depending on the GNP concentration ${ }^{8}$. The DNA-nano interaction is one of the most interesting investigative areas for cancer therapy because of its combined gamma radiation and nanomaterial effects?

The aim of this work is to synthesize and characterize $\mathrm{TiO}_{2}$ NPs, study the interaction of $\mathrm{TiO}_{2}$ NPs with radiation and then estimate the Dose-enhancement Factor (DEF) at different concentrations of NPs under lowenergy excitation (14-35 kV).

\section{Materials and Methods}

TTIP, Titanium Tetraisopropoxide (97\% from Sigma Aldrich); acetic acid and hydrochloric acid (Sigma Aldrich); and isopropyl alcohol (RANKEM) were used.

\subsection{Synthesis of $\mathrm{TiO}_{2}$ Nanoparticles}

$\mathrm{TiO}_{2}$ NPs were prepared by the sol-gel method using Titanium Isopropoxide (TTIP, 97\%, Sigma Aldrich) as a precursor as well as deionized water and isopropyl alcohol (RANKEM). A total of $40 \mathrm{ml}$ of isopropyl alcohol was added to $10 \mathrm{ml}$ of TTIP in a $200 \mathrm{ml}$ beaker to form the first mixture. The first mixture solution was stirred for 30 minutes. For the hydrolysis reaction, we prepared a mixture of hydrochloric acid, $10 \mathrm{ml}$ of deionized water and $10 \mathrm{ml}$ of isopropyl alcohol and then added it dropwise to the first mixture. Then, the final mixture solution was stirred continuously for 4 hours, after which the mixture had converted to a gel. The mixture was centrifuged at $4000 \mathrm{rpm}$, washed and dried. The dried $\mathrm{TiO}_{2} \mathrm{NPs}$ were calcined at $300^{\circ} \mathrm{C}$.

\subsection{X-ray Diffraction (XRD)}

The X-ray Diffraction (XRD) measurements were performed on $\mathrm{TiO}_{2}$ nanoparticle powders using a diffractometer (Bruker Axs D8 Advance, Germany). CuKa radiation $\left(\lambda=1.54^{\circ} \mathrm{A}\right)$ was used at a voltage of $40 \mathrm{kV}$ and a current of $25 \mathrm{~mA}$.

\subsection{Scanning Electron Microscopy (SEM)}

The surface topography of the pure $\mathrm{TiO}_{2}$ nanoparticle powder was characterized using Scanning Electron Microscopy (JXA840 JEOL, SEM, Japan) at an accelerating voltage of $15 \mathrm{kV}$ and a working distance of $10 \mathrm{~m}$. The specimens were sputter-coated with carbon for energy dispersive X-ray (EDX) analysis.

\subsection{Transmission Electron Microscopy (TEM)}

The morphology and size of the $\mathrm{TiO}_{2}$ nanoparticles were characterized using Transmission Electron Microscopy (TEM) using a JEOL 2100F TEM instrument operating at an accelerating voltage of $100 \mathrm{kV}$.

\subsection{Evaluation of the X-ray Absorption of $\mathrm{TiO}_{2}$ Nanoparticle Solutions}

The X-ray measurements were performed using tube voltages between $14 \mathrm{kV}$ and $35 \mathrm{kV}$ at $1 \mathrm{~mA}$. The X-ray beam was generated with a Molybdenum (Mo) anode X-ray tube: $\mathrm{K}_{\alpha}=17.4 \mathrm{keV}$ (71.1 pm), $\mathrm{K}_{\beta}=19.6 \mathrm{keV}$ (63.1 pm). The High Voltage (HV) tube was scanned between $14 \mathrm{kV}$ to $35 \mathrm{kV}$ the $\mathrm{HV}$ range available in our $\mathrm{X}$-ray source.

\section{Results and Discussion}

\subsection{Characterizations}

\subsubsection{X-ray Diffraction (XRD)}

The structure and particles size of the $\mathrm{TiO}_{2}$ nanoparticle powder was determined by X-ray Diffraction. Figure 1 shows the XRD pattern of the $\mathrm{TiO}_{2} \mathrm{NPs}$ powder. Anatase peaks were observed at a $2 \theta$ of $52.47^{\circ}, 55.05^{\circ}, 63.44^{\circ}, 74.50^{\circ}$ and $76.50^{\circ}$; therefore, the major phase of our sample matched with the crystal faces of the anatase $\mathrm{TiO}_{2}$ phase (105), (211), (204), (215) and (301), respectively, crystal planes, card 21-1272, JCPDS]. Rutile peaks are found at $2 \theta$ values of $14.42^{\circ}, 29.62^{\circ}, 44.48^{\circ}$ and $66.75^{\circ}$; these correspond to crystal planes of (001), (110), (210) and (221) (JCPDS Card no. 21-1276). The anatase phase is preserved under $150^{\circ} \mathrm{C}$, while the rutile phase is predominant at temperature higher than $250^{\circ} \mathrm{C}^{10}$. We evaluated the crystallite size from the $\mathrm{X}$-ray diffraction results using the Scherrer equation: $D=K \lambda / \beta \cos \theta$, where $\lambda$ is the wave- 
length of the $\mathrm{X}$-ray radiation, $\mathrm{D}$ is the crystallite size, $\mathrm{K}$ is a constant, $\beta$ is the full width at half maximum (FWHM) $(\mathrm{Cu} \mathrm{Ka}-1$ radiation $=1.54060 \AA)$, and $\theta$ is the Bragg angle of the peak ${ }^{11}$. From the XRD spectrum, the particle sizes ranged from 2-10 $\mathrm{nm}$.

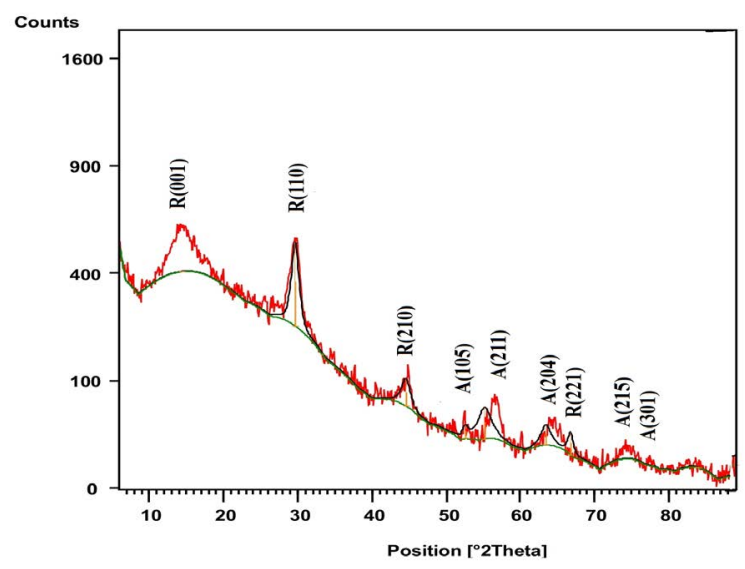

Figure 1. Pattern of the identified phases of $\mathrm{TiO}_{2} \mathrm{NPs}$ powder.

\subsubsection{Scanning Electron Microscopy (SEM)}

Figure 2 shows the SEM images of the prepared $\mathrm{TiO}_{2}$ NPs. The surface morphology of the $\mathrm{TiO}_{2}$ NPs was studied using scanning electron microscopy. The SEM images show that the NP conglomerate caused an increase in the $\mathrm{TiO}_{2} \mathrm{NP}$ size $\underline{12}$ and that the $\mathrm{TiO}_{2} \mathrm{NPs}$ had a uniform spherical morphology. Figure 3 shows the EDX spectrum of the $\mathrm{TiO}_{2}$ NPs. The spectrum shows the chemical constituents present in the sample. The EDX spectrum shows that there is an impurity peak for carbon but that the majority of the sample is $\mathrm{TiO}_{2}$, as shown in Table 1 .

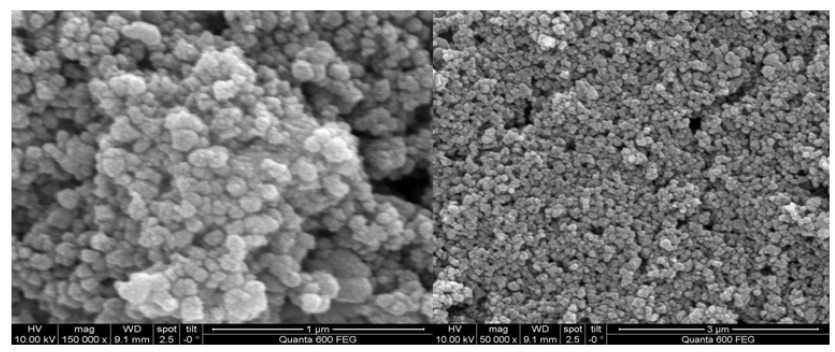

Figure 2. SEM images of prepared $\mathrm{TiO}_{2} \mathrm{NPs}$.

\subsubsection{Transmission Electron Microscopy (TEM)}

The TEM image in Figure 4 shows the presence of nanosized $\mathrm{TiO}_{2} \mathrm{NPs}$, which can be ascribed to the anatase crystal phase. The uniform particles in the image of the
$\mathrm{TiO}_{2}$ NPs might be ascribed to the aggregation of small $\mathrm{TiO}_{2} \mathrm{NPs}$ during the growth of the nanocrystals. Therefore, the growth of these nanoparticles was uncontrolled, and the resulting particles were more aggregated, thus causing the larger particle size seen in the SEM images.

Table 1. The chemical composition of the $\mathrm{TiO}_{2} \mathrm{NPs}$

\begin{tabular}{|l|l|l|}
\hline Element & Wt\% & At\% \\
\hline CK & 07.91 & 18.88 \\
\hline OK & 21.77 & 39.02 \\
\hline TiK & 70.33 & 42.10 \\
\hline Matrix & Correction & ZAF \\
\hline
\end{tabular}

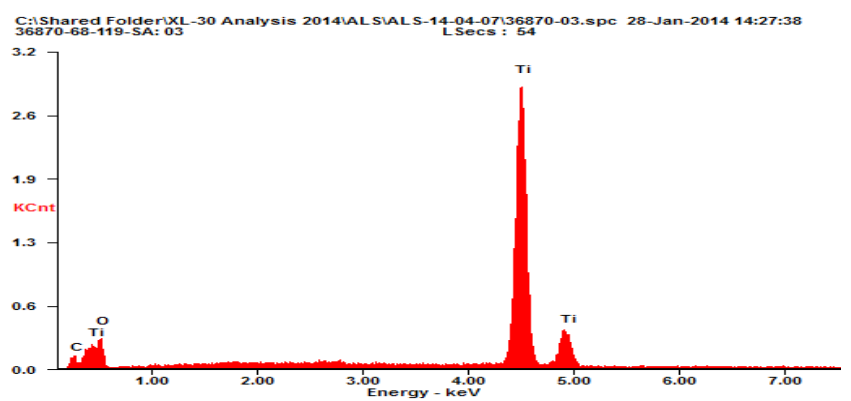

Figure 3. EDX of prepared $\mathrm{TiO}_{2} \mathrm{NPs}$.

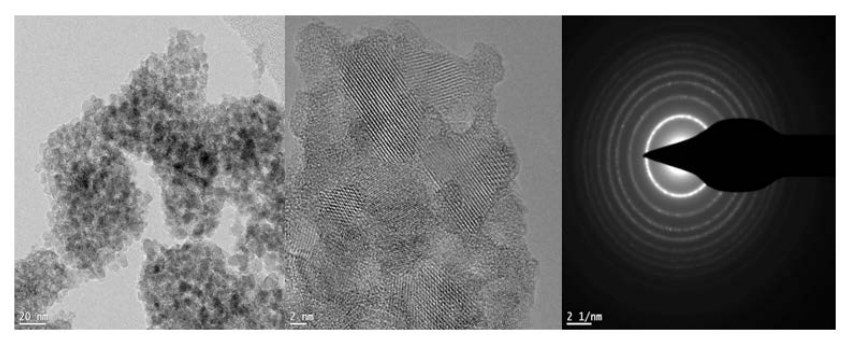

Figure 4. TEM images of the prepared $\mathrm{TiO}_{2} \mathrm{TiO}_{2} \mathrm{NPs}$.

The microstructure of the $\mathrm{TiO}_{2}$ NPs was obviously seen using TEM. In low-magnification images, spherical $\mathrm{TiO}_{2} \mathrm{NPs}$ with an average diameter of $\underline{10} \mathrm{~nm}$ were seen as shown in Figure 4(a), while Figure 4(b) shows the $\mathrm{TiO}_{2}$ NPs at a higher magnification. The single-crystal $\mathrm{TiO}_{2}$ NPs in Figure 4 were identifiable as the anatase phase (01075 -1537, JCPDS), with a spacing of $1.23 \AA$ between the crystal planes.

\section{2 $\mathrm{TiO}_{2}(\mathrm{NPs})$ and Radiosynsitization}

\subsubsection{In vitro Studies of $\mathrm{TiO}_{2}$ NP Solutions}

$\mathrm{X}$-ray beams were transmitted through pure water and $\mathrm{TiO}_{2} \mathrm{NP}$ solutions with different concentration of $\mathrm{TiO}_{2}$ 
NPs (6.66, 13.23 and 20\%). According to Figure 5, we can observe that the $\mathrm{X}$-ray absorption for $\mathrm{TiO}_{2} \mathrm{NP}$ solutions is higher than the absorption of pure water. The amount of absorption increased with increasing $\mathrm{TiO}_{2} \mathrm{NP}$ percentage. At a voltage of $19 \mathrm{kV}$, which is near the k-edge of molybdenum, we see edge effect, for all weight percent samples. This is because X-ray attenuation increases at energies equal to the k-edge of the involved elements ${ }^{13}$.

The effect of an increase in the percentage of $\mathrm{TiO}_{2} \mathrm{NPs}$ on the relative X-ray absorption at different X-ray tube voltages, from 14 to $35 \mathrm{kV}$, is shown in Figure 6. There exists an observable difference in the X-ray absorbance with and without $\mathrm{TiO}_{2} \mathrm{NPs}$.

The maximum relative $\mathrm{X}$-ray absorbance for samples with $\mathrm{TiO}_{2}$ NPs was observed at $14 \mathrm{kV}$ for a $20 \%$ by weight sample of $\mathrm{TiO}_{2} \mathrm{NPs}$. In Figure 6, the results show that the absorbance of samples containing $\mathrm{TiO}_{2}$ NPs under a 14 $\mathrm{kV}$ beam was higher than the absorbance under 24 and $34 \mathrm{kV}$ for all samples with different weight percentages.

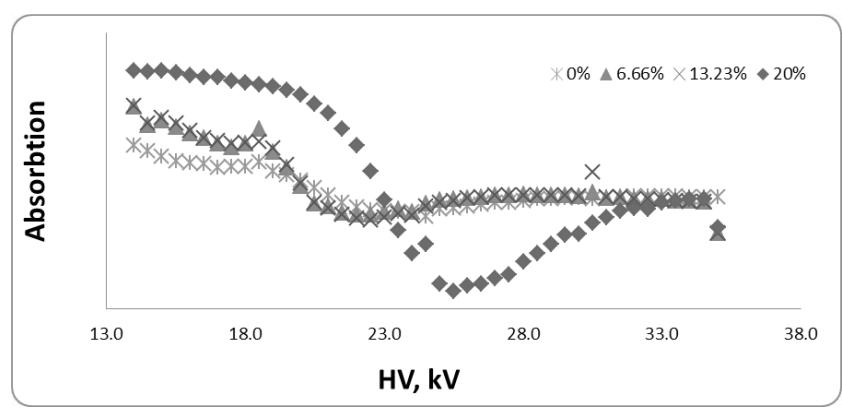

Figure 5. X-ray absorption for pure water and $\mathrm{TiO}_{2} \mathrm{NPs}$ solutions with different percentages of $\mathrm{TiO}_{2}$ NPs.

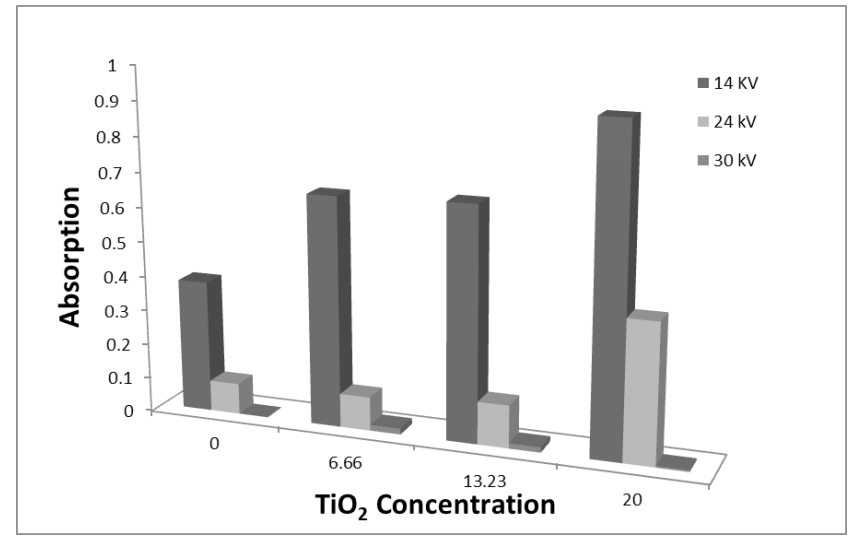

Figure 6. The effect of the $\mathrm{TiO}_{2} \mathrm{NPs}$ percentage on X-ray absorption at different $\mathrm{HV}$.

\subsubsection{Dose-enhancement Factor (DEF)}

The effect of various NP concentrations on dose enhancement was measured at different $\mathrm{HV}$ for $\mathrm{TiO}_{2} \mathrm{NPs}$ in water and NPs solution at room temperature.

Figure 7 shows that the dose is always enhanced for any $\mathrm{HV}$ in the range of $14-35 \mathrm{keV}$ but that the largest dose enhancements are achieved when $\mathrm{HV}$ was $35 \mathrm{keV}$.

This increase is due to lower absorption. The dose enhancement was higher with the addition of $\mathrm{TiO}_{2} \mathrm{NPs}$ due to the capability of promoting photoelectric interactions within NPs of heavy metals. The photoelectric effect occurred in the $\mathrm{kV}$ energy range, but lower $\mathrm{kV}$ energy radiation was capable of deeper permeation ${ }^{14}$.

The best dose enhancements were obtained at the higher concentrations of $\mathrm{TiO}_{2}$ NPs. The Doseenhancement Factor (DEF) increased with increasing $\mathrm{TiO}_{2} \mathrm{NP}$ concentration as shown in Table 2 .

Figure 7 shows the DEF as a function of the $\mathrm{TiO}_{2} \mathrm{NP}$ concentration for three different energy levels (14, 24 and $30 \mathrm{kV}$ ). The Dose-enhancement Factor increased almost linearly with increasing $\mathrm{TiO}_{2} \mathrm{NP}$ concentration. Figure 7 shows the Dose-enhancement Factor as a function of $\mathrm{HV}$ for all three different $\mathrm{TiO}_{2} \mathrm{NP}$ concentrations at 14 $\mathrm{kVexcitation}$. The DEF is maximum at $14 \mathrm{kV}$ for all concentrations.

DEF in the observed range of energy is facilitated by the increased interaction cross-section at the higher Z-number of titanium and the production of Auger electrons ${ }^{15}$. Some of these electrons may participate in dose enhancement.

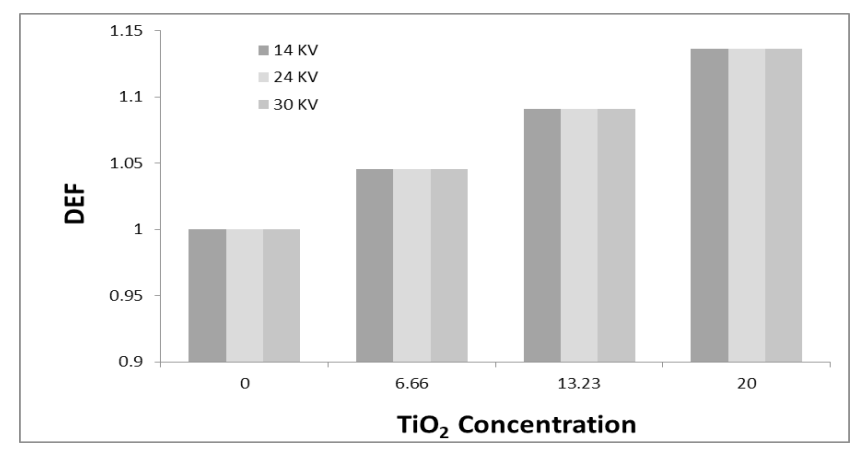

Figure 7. DEF as a function of the $\mathrm{TiO}_{2} \mathrm{NPs}$ concentration for three different $\mathrm{HV}$ values (14, 24 and $30 \mathrm{kV}$ ). 
Table 2. Relation between $\mathrm{TiO}_{2} \mathrm{NPs}(\%)$ and DEF

\begin{tabular}{|l|l|}
\hline $\mathrm{TiO}_{2}$ NPs (\%) & DEF \\
\hline $\mathbf{0}$ & 1 \\
\hline $\mathbf{6 . 6 6}$ & 1.045339 \\
\hline $\mathbf{1 3 . 2 3}$ & 1.090678 \\
\hline $\mathbf{2 0}$ & 1.136017 \\
\hline
\end{tabular}

\section{Conclusions}

$\mathrm{TiO}_{2}$ nanocomposites were prepared by mixing $\mathrm{TiO}_{2}$ nanoparticles in a chitosan polymer. The XRD spectrum and TEM profile exhibited peaks that were assigned to the anatase crystal phase, with particle sizes of $<10 \mathrm{~nm}$. The maximum relative X-ray absorbance for the samples with $\mathrm{TiO}_{2} \mathrm{NPs}$ was observed at $14 \mathrm{kV}$ for a $20 \%$ by weight sample of $\mathrm{TiO}_{2} \mathrm{NPs}$. The optimum HV for the maximum dose enhancement of the $\mathrm{TiO}_{2} \mathrm{NP}$ solution was found to be approximately $14 \mathrm{kV}$ for all concentrations.

\section{Acknowledgements}

The authors would like to acknowledge financial support for this work, from the Deanship of Scientific Research (DSR), University of Tabuk, Tabuk, Saudi Arabia, under grant no. S-1439-0079.

\section{References}

1. Babu EP, Subastri A, Suyavaran A, Rao PL, Kumar MS, Jeevaratnam K, Thirunavukkarasu C. Extracellularly synthesized $\mathrm{ZnO}$ nanoparticles interact with DNA and augment gamma radiation induced DNA damage through reactive oxygen species. RSC Advances. 2015; 5(76):6206777. https://doi.org/10.1039/C5RA09935H

2. Nia MH, Tavirani MR, Nikoofar AR, Masoumi H, Nasr R, Hasanzadeh H, Jadidi M, Shadnush M. Stabilizing and dispersing methods of $\mathrm{TiO}_{2}$ nanoparticles in biological studies. Journal of Paramedical Sciences. 2015; 6(2):69-105.

3. Kavitha K, Prabhu M, Rajendrana V, Manivasankan P, Prabu P, Jayakumar T. Optimization of nano-titania and titania-chitosan nanocomposite to enhance biocompatibility. Current Nanoscience. 2013; 9(3):308-17. https://doi. org/10.2174/1573413711309030003

4. Hainfeld J, Slatkin D, Smilowitz H. The use of gold nanoparticles to enhance radiotherapy in mice. Physics in Medicine and Biology. 2004; 49(18):309-24. https://doi. org/10.1088/0031-9155/49/18/N03
5. Anijdan SHM, Shirazi A, Mahdavi SR, Ezzati A, Mofid B, Khoei S, Zarrinfard M A. Megavoltage dose enhancement of gold nanoparticles for different geometric set-ups: Measurements and Monte Carlo simulation. International Journal of Radiation Research. 2012; 10(3-4):183-6.

6. Cho SH, Jones BL, Krishnan S. The dosimetric feasibility of Gold Nanoparticle-aided Radiation Therapy (GNRT) via brachytherapy using low-energy gamma-/X-ray sources. Physics in Medicine and Biology. 2009; 54(16):4889-905. PMid: 19636084 PMCid: PMC3064075. https://doi. org/10.1088/0031-9155/54/16/004

7. Su XY, Liu PD, Wu H, Gu N. Enhancement of radiosensitization by metal-based nanoparticles in cancer radiation therapy. Cancer Biology and Medicine. 2005; 11(2):86-91.

8. Cho SH. Estimation of tumor dose enhancement due to gold nanoparticles during typical radiation treatments: A preliminary Monte Carlo study. Physics in Medicine and Biology. 2005; 50(15):63-173. PMid: 16030374. https://doi. org/10.1088/0031-9155/50/15/N01

9. Liu Y, Zhang Y, Wang S, Pope C, Chen W. Optical behaviors of $\mathrm{ZnO}$-porphyrin conjugates and their potential applications for cancer treatment. Applied Physics Letters. 2008; 92(14):143901. https://doi.org/10.1063/1.2908211

10. LiW,Liang R, HuA,HuangZ,Zhou YN.Generation of oxygen vacancies in visible light activated one-dimensional iodine $\mathrm{TiO}_{2}$ photocatalysts. RSC Advances. 2014; 4(70):36959-66. https://doi.org/10.1039/C4RA04768K

11. Zhao Y, Li C, Liu X, Gu F, Jiang H, Shao W, Zhang L, He Y. Synthesis and optical properties of $\mathrm{TiO}_{2}$ nanoparticles. Materials Letters. 2007; 61(1):79-83. https://doi.org/10.1016/j.matlet.2006.04.010

12. Sugapriya $S$, Sriram R, Lakshmi S. Effect of annealing on $\mathrm{TiO}_{2}$ nanoparticles. Optik. 2013; 124(21):4971-5. https:// doi.org/10.1016/j.ijleo.2013.03.040

13. Panta RK, Bell ST, Healy JL, Aamir R, Bateman CJ, Moghiseh M, Butlera APH, Anderson NG. Element-specific spectral imaging of multiple contrast agents: A phantom study. Journal of Instrumentation. 2018; 13:1-18. https://doi. org/10.1088/1748-0221/13/02/T02001

14. Celina Y, Kyle B, Wonmo S, Jan S, Devika C. Determining the radiation enhancement effects of gold nanoparticles in cells in a combined treatment with cisplatin and radiation at therapeutic megavoltage energies. Cancers. 2018; 10(5):e150-e150. PMid: 29786642 PMCid: PMC5977123. https://doi.org/10.3390/cancers 10050150

15. Georg H, Philipp M, Gotz P, Vladimir B, Wilhelm K, Hiltraud H, Jens F, Matthias K, Felix B, Frederik W, Michael $H$. Dose enhancement effects of gold nanoparticles specifically targeting RNA in breast cancer cells. PLOS ONE. 2018; 13(1):e0190183. 